\title{
Temporary Public Spaces: A Technological Paradigm
}

\author{
Philip Crowther \\ Queensland University of Technology, Brisbane, Australia \\ Creative Industries Faculty, School of Design \\ p.crowther@qut.edu.au
}

\begin{abstract}
Contemporary cities no longer offer the same types of permanent environments that we planned for in the latter part of the twentieth century. Our public spaces are increasingly temporary, transient, and ephemeral. The theories, principles and tactics with which we designed these spaces in the past are no longer appropriate. We need a new theory for understanding the creation, use, and reuse of temporary public space. More than a theory, we need new architectural tactics or strategies that can be reliably employed to create successful temporary public spaces.

This paper will present ongoing research that starts that process through critical review and technical analysis of existing and historic temporary public spaces. Through the analysis of a number of public spaces, that were either designed for temporary use or became temporary through changing social conditions, this research identifies the tactics and heuristics used in such projects. These tactics and heuristics are then analysed to extract some broader principles for the design of temporary public space. The theories of time related building layers, a model of environmental sustainability, and the recycling of social meaning, are all explored. The paper will go on to identify a number of key questions that need to be explored and addressed by a theory for such developments: How can we retain social meaning in the fabric of the city and its public spaces while we disassemble it and recycle it into new purposes? What role will preservation have in the rapidly changing future; will exemplary temporary spaces be preserved and thereby become no longer temporary? Does the environmental advantage of recycling materials, components and spaces outweigh the removal or social loss of temporary public space? This research starts to identify the knowledge gaps and proposes a number of strategies for making public space in the age of temporary, recyclable, and repurposing of our urban infrastructure; a way of creating lighter, cheaper, quicker, and temporary interventions.
\end{abstract}

Keywords: assembly; disassembly; design; temporary; public space.

\section{To cite this article:}

Crowther, P. (2016). Temporary Public Spaces: A Technological Paradigm. The Journal of Public Space, I(I), 63-74, DOI: I0.5204/jps.vlil.I I

This article has been peer-reviewed and accepted for publication in The Journal of Public Space. Please see the Editorial Policies under the 'About' section of the journal website for further information.

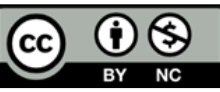

This work is licensed under a Creative Commons Attribution - Non Commercial 4.0 International License. https://creativecommons.org/licenses/by-nc/4.0/ 


\section{Introduction}

While much has been written about the changing nature of our cities and the increasing range of temporary public spaces within them, such writings are largely about the philosophy and planning policy of temporary public spaces (Bishop and Williams, 2012); little has been written about the architectural practicalities of making such spaces. 'Technical manoeuvres have not yet put together a consistent theory as a basis for the new paradigm of public space. The combination of urban tactics and the fear of climate meltdown may spawn a freak, only understood by ecologists and technocrats, which could reduce the design of public space to the basic issues of sustainability, viability, efficiency and durability' (Fernandez Per and Mozas, 2012: 19). With this is mind, this paper seeks to start the process of establishing the architectural needs of such temporary public space. It presents a general survey (through a number of case studies) of temporary public spaces and the architectural technologies that they utilise, to establish a theoretical understanding of the field and practical guidance for the creation of future temporary public space. The paper establishes a number of broad architectural and technological principles for designing temporary public space:

- a model of sustainment; environmental, economic, social

- the recycling of social meaning and sense of place through reused materials - 'spolia'

- time related building layers; the four dimensional city

The objective of this paper is to provide a theoretical analysis of the architectural strategies and technologies used in the creation of temporary public spaces, as illustrated in a number of case studies. This analysis then exposes the common approaches, solutions, and strategies implemented in the successful creation of public spaces. The paper presents a technological paradigm of temporary public space; a model or pattern of solution that has a belief system and a puzzle-solution (Dosi, 1982). This belief system incorporates an understanding of the psycho-social impact of public spaces when they change, and how the disassembly and deconstruction of public spaces can affect the meaning they embody (Denhart, 2009).

\section{The Temporary Nature of Cities}

In the final few decades of the twentieth century, and the first few years of the twenty first, it has become increasingly clear that cities and urban settlements are no longer designed and constructed with the same sense of permanence that is so evident in earlier constructed environments. Our buildings live shorter lives, being demolished after just a few decades to make way for bigger and better developments. The commercial realities of a capitalist society drive such private development at an ever increasing pace. In the midst of this private sector frenzy are the public spaces that we once took as permanent, but which now are likewise responding to a quickening pace of development. Although this phenomenon of shorter lived temporary buildings is more evident now than ever, it is not unique to our contemporary cities.

'Temporary use is not a new social phenomenon: temporary ventures have always been a feature of cities that were conceived and built for the long-term' (Senatsverwaltung für Stadtentwicklung and Denton, 2007: 21). Even whole cities that we tend to think of as permanent or long-lived environments were not always so. Indeed 'history abounds with examples of mighty cities that turned out to be temporary' (Bishop and Williams, 2012: 
12). Even when significant portions of cities survived for decades or centuries, other parts were less long-lived. It is perhaps because those parts have long gone that we tend to focus on the surviving structures.

What appears to be happening in our contemporary cities is however a much more widespread activity of temporary use and short lived constructions. 'Buildings are designed to last 70 to 100 years, yet today buildings with an age of only 15 years are demolished to give way to new construction' (Durmisevic and Yeang, 2009: 134). While buildings have a shorter life expectancy that they did a hundred years ago, the materials and components will last much longer. The city is no longer fixed in time; it is now a four dimensional city (Bishop and Williams, 2012:19). We are experiencing a significant paradigm shift in how our cities are designed and used (Mclntyre, 2009); what Bauman (2000) refers to as 'liquid modernity'.

'The way in which 'public space' is viewed is also changing from a traditional focus on formal squares, parks and pavements to a broader conception that recognises the value of less formal 'left-over' spaces and the everyday uses that occur there' (Bishop and Williams, 2012: 87). Public space is no longer only provided by governments for purposes of social control, but is now about the strategies and tactics used by those who occupy it. Public space is now characterised by freedom of action rather than stringently designed forms; a freedom that recognises the importance of social sustainability, indeterminism, and the importance of the temporary. Cities must now concern themselves with public spaces that operate on ever shortening time scales that accommodate the casual impromptu situation (Fernandez Per and Mozas, 20I2: II-I7). This shift in attitude to the casual, temporary, and publicly determined, evident in numerous governmental changes to legislation (Gerend, 2007), represents a new belief system in the technological paradigm of public space.

\section{Reuse of Construction Materials}

'Nothing is lost, nothing is created, everything is transformed.'

Antoine Lavoisier (French chemist), 1793.

The reuse of building materials and components has always been an important construction strategy. Since ancient times we have salvaged materials from demolished or temporary buildings for use in new construction. 'Buildings have long been mined and harvested for their materials' (Easterling, 2010: 266). There has however been a marked change in the reasoning behind the re-use of construction materials and components over the past two thousand years. Such disassembly and reassembly has been variously motivated by simple economic reason or material shortage, respect for craftsmanship, aesthetic taste, theories of bricolage, desire to express cultural domination or links to past glories, tradition, a desire to restage the past, connection to a sense of place, and most recently by ecological awareness (Meier, 20l I).

Unfortunately with the increasing pace of development and the shortening life span of buildings, we are seeing reducing amounts of reuse and recycling, and increasing amounts of construction and demolition material going to waste. 'The building sector alone absorbs up to $50 \%$ of all material resources globally used, while generating a similar proportion of construction and demolition waste' (Angelil and Siress, 2010: 254). The 
separation between our appreciation of materials in the natural realm and those in the constructed realm is changing. The natural realm is no longer seen as an endless resource and the constructed realm is no longer seen as an everlasting cultural artefact. For example there is now more copper to be found in buildings than in the ground (Ruby and Ruby, 2010: 243). In Europe, the "building industry accounts for 40 percent of waste production, 40 percent of energy consumption and $\mathrm{CO}_{2}$ emissions, and 50 percent of material resources taken from nature' (Durmisevic and Yeang, 2009:134). At the moment only $25-30 \%$ of construction and demolition waste is recycled, but this figure could be as high as 75\% (Leigh and Patterson, 2006: 217). We already have the ability to achieve such levels. 'The impediments to the reuse of construction components are rarely technical or economic. Instead, they are mostly based on organizational, contractual and social structures' (Gorgolewski, 2008: 175). In contemporary industrialised societies there is a widespread disapproval for the reuse of 'second-hand' materials.

It should not however be so. 'Transforming an existing building is not only economically more sound, but also socially more sustainable because one does not need to replace historically developed identities overnight by manufacturing new ones' (Ruby and Ruby, 2010: 245). Not only can we recycle and reuse materials, we can recycle and reuse the social significance embodied in those materials. Such appropriation of historic significance in building materials and components has been practiced for centuries in the form of spolia; the incorporation of fragments of demolished buildings and monuments into new buildings, primarily in order to borrow their cultural significance (Brilliant and Kinney, 20II).

While such reuse is not currently common, there is a slowly increasing awareness of the potential that could be realised in materials and component recovery. 'Building subtraction... is an emergent and aggressive enterprise, within which negative development is a lucrative means of mining the city' (Easterling, 20I0: 265). While the idea of the 'creative destruction' of the built environment and the reuse of existing structures as a resource is being explored (Paterno, 20I2), there is not yet a developed theoretical grounding for its application.

\section{Methodology and Case Studies}

Given the objectives of this research, to develop a new technological paradigm for understanding temporary public space and identifying strategies for achieving such spaces, the research methodology being employed is not one of positivist hypothesis-testing research. Rather the research is guided by a philosophy of soft systems methodology (Checkland and Scholes, 1990). In this approach the research is of an exploratory nature with a less clear vision of predetermined specific outcomes. Such an approach sits well with the goals of this study, the development of value systems and heuristic principles. Soft systems methodology is a way of looking at research into open-ended problems. Checkland and Scholes (1990: 5) define soft systems methodology as 'a process of tackling real-world problems in all their richness... which enables lessons to be learned... and... enables it to be used descriptively to make sense of a complex situation'.

Bearing in mind that it is not the purpose of soft systems methodology research to provide truths and solutions, but rather to investigate problems in a holistic and 
qualitative way, 'lessons to be learned' is a valuable outcome. The use of soft systems methodology to investigate building disassembly and materials recycling has already been used by researchers in this field. Golton, Hiley and Frost (1994: 265) used this methodology to 'assemble the fragmented information and place it in a framework' that relates it to the construction industry. Their proposal to develop a 'model' is consistent with the aims of this paper in developing strategies and a framework; a technological paradigm.

The case study projects that constitute this research are more numerous than can be presented here in full. What follows is a selection of projects that illustrate significant pieces of 'fragmented information'. Overall, analysis has been conducted on the following:

- fun fairs and circus tents

- temporary sport facilities; Olympics, motorsport street-races

- music concerts in stadia

- world Expos; I85I, 1970, 1988, 1992

- community occupation of vacant space, community gardens and similar

- political rallies

- religious or community festivals

- street markets

- a range of longer-term but temporary or adaptable public space buildings, such as; Centre Pompidou, IRCAM Paris, Sainsbury Centre for the Visual Arts, Kentishtown Interaction Community Centre, MOMI tent, Karaza mobile theatre

- a range of unrealised/experimental propositions or research projects, such as; Archigram plug-in City, Fun Palace, Temporary autonomous zones: TAZ (Bey, 199I), Free zone Berlin (Woods, 199I), The Cronocaos project (Koolhaas, 20II) A full review of all types of historic temporary buildings that have been designed for future disassembly has been conducted and presented elsewhere (Crowther, 1999). This paper presents an updated review of case studies with a specific focus on temporary public spaces. Data has been collected primarily from published information, drawings, and photographs of the projects, and where possible first hand from site visits and/or conversations with the designers and builders of the spaces. Case studies have been reviewed for recurrent themes in the approach to the making of public space, and recurrent technical solutions. A form of grounded theory analysis has allowed such recurrent themes and strategies to be exposed.

In particular this research explores what the economist Giovanni Dosi (1982) refers to as a technological paradigm; a model or pattern of solution that has a belief system and a puzzle-solution. In this particular instance the belief system is explored through the facets of a model of sustainment (social, economic, and environmental), and the recycling of social meaning. The puzzle-solutions are explored through the technological strategies for creating temporary public space.

\section{A Model of Sustainment}

Any new paradigm for the built environment cannot fail to consider the current state of society and the environment in regards to future sustainability. As such a model for temporary public space must deal with, or offer guidance on, the sustainment of environmental, economic, and social systems. For example the master planning and major 
stadia for the London Olympic Games of 2012 were based on a philosophy of temporary structures that could be disassembled and reused, and leave an appropriate legacy for the local community. 'The widespread use of temporary buildings as sporting facilities was truly radical, part of a sustainability strategy that argued it was wrong for a city to burden itself with facilities it didn't need' (Slavid, 20I2). The London stadium was designed specifically to be partly disassembled in order to down-size the stadium capacity after the games. The stadium was the lightest Olympic stadium to date according to the Olympic Delivery Authority; requiring approximately only one quarter of the structural steel used in the Beijing Olympic Stadium (Olympic Stadium, 20I2). The embodied energy in a stadium (as a building type) is typically much higher than other building types, due to the infrequent use of the stadium. Embodied energy can be as much as $60 \%$ of the lifetime energy load (Olympic Stadium, 20I2); as such it was important to seek ways to recover and reuse that embodied energy through reuse of materials and components.

Not only were environmental and economic concerns driving this design decision, the London Olympic Committee specifically set up a 'Legacy Board' that looked at the future of the temporary facilities as well as the future of the site itself from a social and community perspective. As such, the three dimensions of sustainability were engaged.

\section{Recycling of Social Meaning through Material Reuse}

Although this consideration of social meaning is related to the third dimension of sustainability presented above, it is worth a separate discussion as it is a very much overlooked aspect of the use and reuse of temporary materials and components (Denhart, 2009: 196). The deliberate appropriation of cultural significance from the reuse of building materials and components (traditionally significant stone sculptures and reliefs, columns, decorative elements, and the like) has a long and ancient history (Brilliant and Kinney, 20II). The archaeological term of 'spolia' is given to this practice; the term deriving from the appropriated goods (typically weapons) taken upon winning a battle. While there are numerous ancient examples of this practice its contemporary equivalent is less understood, though none the less significant.

The social meaning held in places, and in the building materials and components of those places is well described by the group of academics and students who disassembled and recycled an important 'public' structure in an African American community in South Carolina U.S.A. The participants noted that it was 'a cultural object' for which there would be 'political implications', and that there was an 'underlying belief that the site had more presence in the community than simply the material at hand' (Erdman, 2006: 19). When the large sail-like canopies from the temporary World Expo of 1988 in Brisbane, Australia, were disassembled for reuse in new public spaces across the city, they took with them a cultural memory of the Expo itself; the new locations became associated with the Expo (Expo Pavilion Recycling, 1991). This was not just the capturing and recycling of the physical structures, but also of the social meaning in them. Just as we might capture and recycle the embodied energy, we can capture and recycle the social energy (Meier, 20II). 


\section{Time Related Building Layers}

The idea that all buildings are impermanent and that different parts have different life expectancies has been well explored and documented (Brand, 1994). How this understanding relates to, or should relate to, the design of temporary buildings has also been explored (Crowther, 2009). 'Cities are formed by highly heterogeneous material composites made from a range of partially incompatible parts, all transforming at different rates of velocity in mutually dependent flows' (Angelil and Siress, 20 I0: 254). This incompatibility of the parts means that they should be designed to be separated on different time scales. The importance of designing buildings in which we separate the structure, the cladding, the services, the internal space planning, and the furniture has been well documented (Duffy and Henney, 1989).

The theory has not however been well developed to accommodate public spaces, neighborhoods, suburbs, and cities; the broader layers of the built environment that sit beyond the scale of the single building. There have been hypothetical explorations of public spaces at the larger scale, such as those of the Archigram group in the 1960's (Cook, et. al. 1972), but no empirical research into temporary public spaces, despite recognition for the need for such an understanding (Mclntyre, 2009). The very short time frame of most temporary public activities, sits in stark contrast with the relative permanence of the space itself. 'Right now, the capacity to occupy public space is immediate. The time factor of tactics has changed as the time scales are shorter' (Fernandez Per and Mozas, 2012: 17). Now, more than ever, there is a need to design public spaces as temporary spaces.

\section{Strategies and Tactics}

Consideration of the case studies against these overarching issues (belief systems) reveals a number of commonly occurring technological strategies that have facilitated the assembly and disassembly of temporary public spaces. Below are a number of such strategies that can be used to guide the design and construction of such public spaces. These strategies have also been shown to facilitate lighter structures, constructed with cheaper budgets, and assembled and disassembled in quicker time.

\section{Minimise the number of different types of building components}

This strategy has the potential to reduce time and cost during both assembly and disassembly through the economy of repetition in these procedures. While it is important to limit the number of different types of components in the whole building, it is more important to limit the number of different types of components in each individual timerelated layer of the building. If different layers are disassembled at different times, there is less benefit to be gained in the layers using the same limited pallet of components.

\section{Use mechanical not chemical connections}

The use of mechanical connections will allow for repeated and easier assembly and disassembly of components for maximum resource and component recovery. This is one of the more important principles that will require one of the greatest departures from the current construction practice of glues and chemical connections. There is however likely to be an increase in time and cost both during assembly and disassembly; but this is 
offset by significant reductions in time and cost in the reuse of components or whole building systems.

Use an open building system

An open building system (one in which parts of the structure can be interchanged and are not bespoke to just one function or location) will facilitate broader compatibility and greater opportunity for component reuse in other temporary projects and in different location on the same project, to facilitate maximum resource reuse after disassembly. There is also the increased opportunity for minor building alterations during the operation of the building with only minimal impact on cost and material consumption.

\section{Use modular design}

Dimensional and functional modularity will greatly reduce the time for assembly and disassembly (and reduce cost through reduced labour time). It will also increase the opportunity for component reuse between different buildings to maximise resource reuse. There may however be times when components may need to be made larger than optimal to comply with acceptable modular standard dimensions. Such minor increases will result in increased use of materials and increased weight; these increases must be balanced against the benefits of modular design.

\section{Use common tools and equipment}

The use of common construction technologies, those widely used within the current building industry, will increase the efficiency of assembly and disassembly. While some current technologies may use slightly more materials and be heavier, it is likely that the savings in time and cost will be greater. Decisions about such technologies require careful life cycle consideration and must be taken with potential and likely future technological developments in mind; and the associated potential savings in material, cost and time.

Provide access to all parts of the structure Increased access will make assembly and disassembly easier and is likely to produce increased levels of future resource recovery. The provision of such access may however, particularly if from the inside of the structure, result in the need for additional space and increased floor area. While examples show that significant levels of access can be achieved with only minor increases in the scope or scale of construction, consideration needs to be given to the desire to minimise materials, time and cost in the initial assembly stage.

Make components sized to suit the means of handling Increased ease of handling, though the reduction in weight or size, will make the future option of disassembly more attractive and increase the ability to maximise material reuse. Consideration should also be given to the cost and time impacts associated with the means of handling, both during assembly and disassembly. Different sized components may allow, or require, different means of handling that will negatively affect time and cost. 
Provide a means of handling and aligning components

There are likely to be few negative impacts associated with this principle. Just minor changes in the form of components will greatly increase the ability to repeatedly handle them and increase the ability to maximise reuse and reduce cost and time.

Provide realistic tolerances for repeated use Increased dimensional tolerances (beyond standard construction practice) will reduce the potential for damage to components during repeated assembly and disassembly. This will encourage the repeated cyclic reuse of components to maximise cost savings. Increased tolerances may require connection systems beyond the scope of common building practice. As such there may be a conflict with the desire to use common tools and equipment (see earlier strategy). It is also possible that increased tolerances may have an increased negative impact during the operational stage of the space, where durability and operability are major concerns. Any significant departures from common practice will require full life cycle consideration.

Use a minimum number of connectors

A reduction in the number of connectors will reduce the time and therefore cost required for the assembly and disassembly process. In order for components to be securely fixed with fewer connectors it may however be necessary to increase the structural capacity of some component. This would have an associated increase in material and weight and this would need to be evaluated against the benefits.

Use a minimum number of different types of connectors

Reducing the number of different types of physical operation needed to achieve assembly and disassembly will reduce time and cost. Such standardisation will also reduce the need for multiple types of tools and reduce the training of builders and users. It is however likely that optimisation of connectors will be compromised, and that some connections will be over designed for their intended function in order to comply with a limited pallet of component connectors. There may be some minor weight increase impacts associated with this compromise.

Design to withstand repeated reuse

Designing joints and connectors to withstand repeated reuse is likely to involve increased durability through increased structural capacity, which may increase the weight of the component. Any such increase must be balanced against the advantages of repeated life cycle reuse of such components and the associated ability to minimise material use in the longer term.

Allow for parallel assembly

Designing for parallel assembly and disassembly, the ability to remove various components in parallel rather than having to disassemble them sequentially will make access and disassembly easier, and therefore quicker and cheaper. There are however likely to be significant redundancies introduced into the design. In a scenario similar to the separation of time-related building layers, such as the separation of structure and cladding, it is likely that increased parallel assembly and disassembly will require increased building 
infrastructure such as support frames and multiple connection systems; all with an associated increase in weight.

Provide identification of building component type

The ability to easily and accurately identify components will reduce the time and cost of assembly and of sorting and re-processing components after disassembly. It will also allow for confident reuse of components, knowing their structural or functional capacity, thereby reducing material use in the longer time frame. Provision of such information should have very minimal negative impact.

\section{Use a standard structural grid}

The use of a dimensional structural grid, and its repetitive nature, will allow for faster assembly and also will facilitate better levels of disassembly through improved relocation compatibility. The grid should relate to the optimal structural capacity of materials and components to reduce material consumption and reduce weight. This may however conflict with a grid set out related to the functional use of the spaces of the building. Such conflict could result in the inefficient use of space and materials, and the inability to minimise resource consumption during the construction stage.

Use prefabrication and mass production

The off-site production of components in factory production facilities has the potential to produce lighter weight components that maximise material efficiency. Manufacture in such factory conditions is also usually faster and cheaper than on-site construction. There is also the opportunity to optimise the use of materials and energy during the stage of production, as well as during construction and deconstruction. Prefabrication and mass production should also be compatible with the use of an open building system and modular design. As such the associated impacts of those strategies must also be considered.

Use lightweight materials and components

The use of lightweight materials will result in lightweight components that are easier and quicker to assemble and disassemble. It is however necessary to consider the full life cycle impacts of the lighter material selection. The lightest appropriate material may have significant negative environmental impacts associated with its manufacture, use and disposal. A full life cycle assessment is required to establish optimal material selection to ensure full protection of the natural environment.

\section{Identify points of disassembly}

Accurate and reliable information of points of, and procedures for, assembly and disassembly will reduce the risk of component and material damage during repeated handling, and increase the potential for recovery to maximise material reuse. The provision of such information should have only minimal negative impact.

Sustain all information about the building/space

The retention of all information relating to public space structure, its component and materials, and their potential reuse and recycling is important in order to realise the full 
potential of future disassembly. Such information will ensure fast and cost effective disassembly of the structure. While such information retention will require careful consideration during the development, planning, design, and construction stages of the project there will be only minimal negative environmental impacts associated with this information management.

\section{Conclusion}

What we discover from the case studies and the derived strategies is that it is very difficult to maximise all three aims of lighter, cheaper, and quicker. In most instances, high achievement in one of these areas comes at the expense of the others, or at the expense of the quality of the public space itself. That is to say in order to achieve all three to a high level it is likely that there may be compromises in how well the space performs architecturally. While it is possible to produce a quality temporary public space that is light, cheap, and quick to create, this will require careful consideration of the above strategies and awareness of the issues of sustainability, varied time-related building layers, and the importance of social meaning and embodied cultural memory.

With the shortening life span of 'permanent' buildings and the increasing number of temporary public spaces, the architectural profession 'is currently mutating from a producer of monuments to a curator of their transformation' (Ruby and Ruby, 2010: 246). Designers need to develop a different understanding of how to make public space for transient use; how to engage with a new technological paradigm with facets of belief systems and technical solutions. 'Interim uses have beautified lots, revitalised neighbourhoods through active uses, and restored nature to stark urban landscapes' (Gerend, 2007: 26), but architects, planners and other designers must now engage with a deeper understanding of the social, cultural, economic and environmental impacts as well as maximising technical solutions.

\section{References}

Angelil, M. and Siress, C. (2010). “Re: Going Around in Circles”. In Ruby, I. and Ruby, A. (2010). Re-Inventing Construction. Zurich: Holcim Foundation for Sustainable Construction.

Bauman, Z. (2000). Liquid Modernity. Cambridge: Polity Press.

Bey, H. (199I). T.A.Z.: The Temporary Autonomous Zone, Ontological Anarchy, Poetic Terrorism. Brooklyn: Autonomedia.

Bishop, P. and Williams, L. (2012). The Temporary City. London; New York: Routledge.

Brand, S. (1994). How Buildings Learn: What Happens After They're Built. New York: Viking.

Brilliant, R. and Kinney, D. (20I I). Reuse Value: Spolia and Appropriation in Art and Architecture from Constantine to Sherrie Levine. Farnham: Ashgate.

Checkland, P. and Scholes, J. (1990). Soft Systems Methodology in Action. Chichester: John Wiley \& Sons.

Cook, P., Chalk, W., Crompton, D., Greene, D., Herron, R. and Webb, M. (eds.) (1972). Archigram. London: Studio Vista.

Crowther, P. (1999). "Historic Trends in Building Disassembly". In Technology in Transition: Mastering the Impacts - ACSA/CIB 1999 International Science and Technology Conference, June 1999, Montreal, Canada. 
Crowther, P. (2009). "Designing for Disassembly”. In Newton, P., Hampson, K., and Drogemuller, R. (Eds.) Technology, Design and Process Innovation in the Built Environment. Abingdon: Taylor and Francis, Pp. 224-237.

Denhart, H. (2009). "Deconstructing disaster: Psycho-social impact of building deconstruction in Post-Katrina New Orleans". In Cities. 26 (2009): 195-20I.

Dosi, G. (1982). "Technological Paradigms and Technological Trajectories”. In Research Policy, no. II, Pp. 147-162.

Duffy F. and Henney, A. (1989). The Changing City, London: Bulstrode Press.

Durmisevic, E. and Yeang, K. (2009). "Designing for Disassembly (DfD)”. In Architectural Design. 79 (6): I34-I37.

Easterling, K. (20I0). “Architecture to Take Away”. In Ruby, I. and Ruby, A. (20I0). Re-Inventing Construction. Zurich: Holcim Foundation for Sustainable Construction.

Erdman, J. (2006). "Studio South: Recycling an African American Landmark". In Journal of Architectural Education. 59 (4): 19-25.

"Expo Pavilion Recycling". (I99I). In Building Construction Materials and Equipment. 32 (I5): 8-9.

Fernandez Per, A. and Mozas, J. (20I2). Strategy and Tactics in Public Space. Amsterdam: A+T.

Gerend, J. (2007). "Temps Welcome: How temporary uses can revitalize neighborhoods". In Planning. December 2007: 24-27.

Golton, B. L., Hiley, A. and Frost, S. (1994). "Development of a Model of Environmental Impact Use and Recycling of Building Demolition Materials". In Sustainable Construction, Proceedings of the CIB TG 16 conference, November 6-9, Tampa, Florida.

Gorgolewski, M. (2008). “Designing with reused building components: some challenges”. In Building Research \& Information. 36 (2): I75- 188.

Koolhaas, R. (201I). "Cronocaos". In Log. Winter, 21: II9-123.

Lavoisier, A. (1793). Traite Elementaire de Chimie. Paris: Cuchet.

Leigh, N.G. and Patterson, L. M. (2006). "Deconstructing to Redevelop". In Journal of the American Planning Association. 72 (2): 217-225.

Mclntyre, A. (2009). "paraSite: Repurposing Suburbia”. In Dimensions. 22: 175-I84.

Meier, H. (20II). "Spolia in Contemporary Architecture: Searching for Ornament and Place". In Brilliant, R. and Kinney, D. (20II). Reuse Value: Spolia and Appropriation in Art and Architecture from Constantine to Sherrie Levine (pp. 223-236). Farnham: Ashgate.

“Olympic Stadium Populous Architects”. (20I2). In Architectural Record. 200 (6): 92.

Paterno, D. L. (20I2). "Recycle and/or Restore: "Re-Cycle: Strategies for Architecture, City, and Planet," Museo Nazionale delle Arti del XXI secolo (MAXXI)". In Future Anterior. 9 (2): I I2I2I.

Ruby, I. and Ruby, A. (20I0). "Mine the City". In Ruby, I. and Ruby, A. (20I0). Re-Inventing Construction. Zurich: Holcim Foundation for Sustainable Construction.

Senatsverwaltung für Stadtentwicklung, and Denton, J. (2007). Urban Pioneers: Berlin: Temporary use and Urban Development in Berlin. Berlin: Jovis.

Slavid, R. (20I2). "Pavilions and Temporary Buildings". In Architects' Journal. 10/4/2012: 58-59.

Woods, L. (199I). Free Zone Berlin. Berlin: Aedes. 